\title{
A imagem de executivos na mídia: um estudo com jornais de Québec
}

\author{
The image of executives in the media: a study of newspapers in Québec
}

\author{
Andréa Leite Rodrigues ${ }^{1}$ \\ Estelle Morin ${ }^{2}$ \\ Suzane Strehlau ${ }^{3}$
}

\section{Resumo}

Morin, Giroux e Pauchant (2001) elaboraram uma pesquisa sobre a identificação de práticas de reconhecimento profissional com executivos do Ministério da Saúde e Serviço Social da Província de Québec, no Canadá. No estudo, os executivos revelaram não sentirem reconhecimento pela sua atuação profissional por parte da população, a qual seria influenciada tanto pela mídia eletrônica quanto impressa, fato que os desmotivava, corroborando, assim, processos de esgotamento psíquico e de perda de sentido do trabalho. $A$ partir dessa constatação, realizamos um estudo para identificar a imagem veiculada pelos jornais sobre trabalho dos executivos de alto nível da Rede de Saúde e Serviço Social de Québec (RSSSQ). Analisamos as notícias de 10 jornais quebequenses publicadas no período 1993-2003. O método empregado foi o de natureza qualitativa, utilizando-se duas técnicas de pesquisa: a construção de corpus de textos e a análise de conteúdo. A constatação foi a de que os jornais veicularam uma imagem pública dos executivos associada às idéias de vitima, de recursos e de reivindicação. Ao final, este artigo oferece breves sugestões para que a mídia possa ser uma co-produtora de significados positivos em relação aos executivos da RSSSQ.

Palavras-chave: trabalho, mídia, construção de corpus, análise de conteúdo, imagem, construção de sentido.

Abstract

Morin, Giroux e Pauchant (2001) researched professional recognition identification practices among Health and Social Services' executives from Quebec, CA. Interviewees reported a lack of recognition by the population, partially influenced by midia content, which caused demotivation and contributed to their burn out and loss of meaning of work. Upon this, a study was carried on to identify the image built by the 10 most important newspapers in this province between 1993-2003. The qualitative method applied was supported by corpus design and content analysis. Results indicate that newspapers presented executives as victims, resources and claimers. Finally, we proposed brief actions that can be taken in order to transform newspapers in positive meaning co-producers for executives.

Keywords: work, midia, corpus design, content analysis, image, sense making.

\footnotetext{
${ }^{1}$ Doutora em Administração de Empresas pela Fundação Getulio Vargas/Escola de Administração de Empresas de São Paulo - FGV/EAESP. Professora do Programa de Mestrado e Doutorado em Administração da Universidade Nove de Julho e dos Cursos de Graduação e de Especialização em Administração da FGV/EAESP.Endereço: Av. Francisco Matarazzo, 612. Prédio C - 20 andar. Água Branca - São Paulo/SP - Brasil. - CEP: 05001-100 - E-mail: rodriguesal@uninove.com.br

${ }^{2}$ Doutora em Psicologia pela Universidade de Montréal. Professora titular da HEC Montréal. Endereço: 3000, chemin de la Côte-Sainte-Catherine. Montréal (Québec) Canada. H3T 2A7. E-mail: estelle.morin@hec.ca

3 Doutora em Administração de Empresas pela Fundação Getulio Vargas/Escola de Administração de Empresas de São Paulo - FGV/EAESP. Professora do Programa de Mestrado Acadêmico em Administração do Centro Universitário da FEI e do Curso de Graduação em Administração da ESPM- SP. Endereço: Rua Tamandaré, 688. Liberdade - São Paulo/SP - Brasil - CEP: 01525-000. E-mail: sstrehlau@fei.edu.br

Artigo submetido em outubro e aceito em dezembro de 2008
} 


\section{Introdução}

Os veículos de comunicação de massa constituem uma fonte importante para desenvolvermos nossa percepção e compreensão não só do mundo, mas de nós mesmos. Não é novidade dizer que vivemos em "um mundo mediado", com excesso de mensagens e variados meios de persuasão. A mídia, eletrônica ou impressa, de massa ou de nicho, compõe um poderoso espaço para práticas humanas de comunicação, que articula texto, imagem e som de um modo que cria, transmite e mantém significados (CASTELLS, 2003).

As notícias publicadas em jornais se dirigem a públicos variados e amplos, por meio de material composto por textos e imagens que misturam informação e publicidade. Se escolhermos um determinado tema e procedermos a um estudo longitudinal, teremos uma análise histórica crítica sobre percepções, crenças e sentimentos que são produzidos no público leitor em conseqüência da interação com as notícias. Segundo Silverstone (1999), a mídia não é uma força desencarnada operando contra nós, mas parte de uma realidade da qual participamos, que dividimos e sustentamos por meio de nossa fala e de nossas intervenções diárias. Portanto, seja impressa ou eletrônica, ela não é um instrumento neutro de difusão da informação. Indo além, Chomsky e Herman (1988) colocam que as organizações que controlam a mídia de massa possuem o poder de conduzir a opinião pública de acordo com uma agenda própria de interesses (the agenda setting). O que se lê é o que se fala, num processo dinâmico no qual a informação é produzida e publicada, ao mesmo tempo em que é discutida, comentada e disseminada, influenciando diretamente o modo de agir das pessoas. em relação ao conteúdo veiculado.

Este artigo resulta de uma pesquisa cujo objetivo foi levantar a natureza das notícias publicadas por jornais da província de Québec, no Canadá, cujo conteúdo aludisse ao trabalho de executivos gestores da Rede de Saúde e Serviço Social de Québec (RSSSQ, no original, Réseau de la Santé et des Services Sociaux du Québec). O objetivo específico foi compreender como a mídia impressa participava da construção de uma imagem dos executivos, analisando notícias publicadas em 10 jornais da referida província, no período 1993-2003. Para tal, aplicamos um método baseado na análise de conteúdo de um corpus de artigos publicados nesse intervalo de tempo. Consideramos o texto como fonte da linguagem sobre a qual a percepção da realidade foi construída pelos leitores. Não há apreensão da realidade, exceto por meio da intervenção da linguagem (linguistic turn); ou seja, todos conceitos e percepções quanto ao que seja verdade são construídos pela linguagem (O'SHAUGHNESSY; O'SHAUGHNESSY, 2007, p.64). Deste modo, partimos da hipótese de que conhecendo o que é publicado nos jornais a respeito dos cadres, saberíamos como a população vê seu desempenho e sua atitude na gestão de serviços públicos. Trata-se de estudar como práticas discursivas (SPINK e FREZZA, 2000) acabam influenciando o reconhecimento profissional (DEJOURS, 1993) de gestores do serviço público.

\section{Antecedentes e justificativa}

O sistema de saúde e de serviços sociais de Québec é constituído por uma vasta rede de estabelecimentos que inclui hospitais, organizações comunitárias, centros de hospedagem e de estadia curta e prolongada, além de clínicas médicas, de reabilitação e de amparo à infância e à juventude, entre outras organizações voltadas à saúde e ao bem-estar social. De acordo com o Bureau de Personnel do Ministério da Saúde e do Serviço Social do Québec (CANADÁ, 2008), classifica-se o contingente de pessoal em três grandes grupos:

- professionels - profissionais especializados, ligados a conselhos de categorias, como médicos, enfermeiros, assistentes sociais, psicólogos e nutricionistas, entre outros;

- fonccionaires - profissionais voltados para ocupações administrativas gerais e de suporte, mas sem responsabilidade gerencial;

- cadres - executivos em funções pertinentes à gestão de recursos e à tomada de decisões em nível gerencial. De acordo com a Association des Cadres Supérieurs de la Santé et des Services Sociaux 
(ACSSSS), são gestores cuja principal responsabilidade é organizar e coordenar os recursos humanos, materiais, informacionais e financeiros dos estabelecimentos de saúde e dos serviços sociais de Québec (ASSOCIATION..., 2008).

Os cadres, executivos ou gestores constituem o objeto de estudo desta pesquisa. Entre 1991 e 2000, o ministério passou por uma sensível diminuição de pessoal, da ordem de 39\% do total de postos. No caso dos executivos (cadres), tal baixa chegou a 59\%. Essa queda no volume de pessoal pode ser reputada à grave crise que se abateu sobre todo o sistema de saúde e serviço social na província do Québec, no período 1990-2002 (CANADÁ, 2008). Para conhecê-la, vale assistir ao filme de Deny Arcand, As invasões bárbaras (de 2003), que expõe um retrato da difícil e decadente situação do serviço público em Québec. O envelhecimento da população, a redução do Estado, a corrupção e a má gestão dos recursos são alguns dos motivos apontados no filme como causadores da maior crise já vista em todo o sistema.

No caso dos cadres, a diminuição de pessoal esteve diretamente relacionada aos casos de aposentadorias precoces por doenças como stress e esgotamento psíquico, além de casos de burn-out. O ministério buscou auxílio para enfrentar essa situação, contratando uma equipe de professores da HEC-Montreal para desenvolver uma investigação dos sentidos do trabalho e das fontes de reconhecimento profissional, com o intuito de esclarecer as causas de tamanha diminuição do número de gestores. Os resultados estão resumidos em Morin, Giroux e Pauchant (2001).

Um dos fatores apontados pelos executivos como causador de stress foi a falta de reconhecimento pela população, em geral, de seus esforços na gestão dos serviços públicos diante de uma crise exacerbada e das restrições nos recursos. Durante entrevistas e intervenções, os executivos manifestaram o sentimento de que não são reconhecidos profissionalmente, sensação reforçada pela imagem de incompetentes e de quem pouco se importa com a gestão da saúde pública que lhes seria atribuída pela mídia. Ainda em Morin, Giroux e Pauchant (2001), encontramos uma lista com as práticas de reconhecimento profissional que esses executivos consideravam importantes. A partir daí, foi possível formular recomendações e estabelecer planos de ação visando à maior valorização do trabalho dos cadres e à elevação de sua auto-estima.

Do ponto de vista acadêmico, esta pesquisa intenta ser uma contribuição para os estudos sobre a relação das pessoas com as chamadas indústrias criativas, nas quais os jornais estão inseridos. A mídia cria imagens que geram consequiências sobre as pessoas, que, por sua vez, participam da geração dos fatos. No caso em estudo, consideramos que os executivos da RSSSQ, na lida cotidiana, participam da formação da sua imagem, como co-produtores de significado. No entanto, recebem simultaneamente um retorno pessoal formado pelas notícias publicadas pelos veículos de comunicação. Isto é, a mídia e os executivos estão juntos na elaboração do significado, o que reflete a crescente importância das indústrias criativas e culturais no cotidiano das pessoas.

Este artigo está organizado da seguinte forma: na sequiência, apresentaremos conceitos sobre a mídia como prática discursiva e reconhecimento no trabalho; logo depois, os procedimentos adotados para a construção do corpus de textos utilizados e a forma de interação com o material empírico. Por fim, os resultados da pesquisa, com as categorias de análise e conclusões a partir de interpretação.

\section{Práticas discursivas e a construção de sentido: o papel da mídia}

Como damos sentido ao mundo onde vivemos? É interessante conhecer um pouco sobre o construcionismo, perspectiva teórica com desdobramentos na psicologia social e na sociologia do conhecimento, para tentarmos responder a tal questão. Trata-se de entender como o conhecimento do mundo se dá via interações entre sujeito e objeto, apresentando, portanto, características de ambos. Um trecho do estudo de Spink e Frezza nos esclarece o que é o construcionismo.

Na perspectiva construcionista, tanto o sujeito como o objeto são construções sócio-históricas que precisam ser problematizadas e desfamiliarizadas. Acatar essa afirmação, entretanto, implica 
problematizar a noção de realidade. Alguns dos pensadores construcionistas acabam por acatar uma dupla noção de realidade, pautada, por um lado, pelo realismo ontológico (ou seja, a postulação da existência da realidade) e, por outro, pelo construcionismo epistemológico, ou seja, a postulação de que a realidade não existe independentemente de nosso modo de acessá-la. Isso significa que é o nosso acesso à realidade que institui os objetos que a constituem. Dito de outra forma, só apreendemos os objetos que se nos apresentam a partir de nossas categorias, convenções, práticas, linguagem: enfim, de nossos processos de objetivação. (SPINK; FREZZA, 2000, p.28).

O construcionismo incorpora a noção de que tudo que utilizamos para explicar, descrever ou escolher entre opções que se apresentam em nossas vidas são produtos de nossas convenções e das ordens morais legítimas em nossa cultura. O desafio está em entender como surgem essas convenções e como existem e se institucionalizam ao longo do tempo. Aqui entra o conceito de práticas discursivas.

Está fora do escopo deste artigo oferecer contribuição inovadora a estudos tão complexos e amplos como os que tratam da linguagem como uma prática social. Para nós, basta ressaltar que a linguagem tornou-se foco de interesse para autores interessados na compreensão do poder dos discursos, relacionando saber e poder. Práticas discursivas remetem à linguagem em ação. Isto é, à maneira como as pessoas constroem sentido e se posicionam em relações sociais cotidianas. As conversas, as falas, as narrativas, os textos e todas as maneiras nas quais se emprega a linguagem são práticas interativas nas quais pessoas falando, ouvindo ou lendo participam da construção social do mundo; ou seja, constroem sentidos (SPINK; MEDRADO, 2000). O discurso é uma forma lingüística regular, na qual se pode reconhecer tendências e modos de conferir sentido ao mundo, institucionalizados, que constituem as práticas discursivas.

Segundo Medrado (2000), a mídia introduziu transformações substantivas nas práticas discursivas cotidianas, ou seja, na forma como as pessoas produzem sentidos sobre fenômenos sociais e se posicionam em relação a eles. Textos e imagens publicados em jornais, revistas, livros ou apresentados na TV, no rádio ou na Internet constituem instrumentos midiáticos que assumem papel fundamental na construção e na seleção de repertório, dada sua afluência de público e, conseqüente, influência no cotidiano das pessoas.

A interação mediada envolve diretamente o uso de meios técnicos como papel, cabos e ondas eletromagnéticas, entre outros recursos que permitem que os conteúdos lingüísticos sejam passados de uma pessoa a outra, mesmo que estas se encontrem distantes espacial e/ou temporalmente. Não há necessidade de se estar no mesmo tempo e espaço para compartilhar um conteúdo apresentado por um jornal ou por um programa de TV, por exemplo. No entanto, continua a haver interanimação dialógica, ou seja, trocas simbólicas entre os falantes. Por isso, a mídia constitui um recurso poderoso na circulação de repertórios e na construção de sentidos.

Spink e Frezza (2000) afirmam que a mídia propicia um espaço fluido, sem fronteiras espaciais e temporais, que leva à reconceituação da divisão estabelecida na modernidade clássica entre privado e público. Tem-se, conseqüentemente, que qualquer fenômeno social que passe por interação mediada, assume um lugar importante nas discussões cotidianas (THOMPSON, 1995a).

A importância dos meios de comunicação de massa na definição do conteúdo de interações face a face fez com que Bauer (1998) definisse a mídia de massa como um "indicador cultural" que pode servir como documento de representação social de um termo ou assunto. Conhecer um conteúdo utilizando o que foi publicado sobre ele em um meio de circulação de massa significa entender um modo de construção de sentido que tem alta capacidade de inserção social e de projeção de imagens em larga escala. Um assunto apresentado a uma audiência por meio de uma interação mediada não se esgota no momento de produção, mas na interação entre leitor/telespectador/ouvinte e conteúdo da mensagem. Não existe, portanto, a clássica separação entre emissão e recepção. Há apenas uma distinção temporal. A interanimação dialógica (trocas simbólicas entre os falantes que se animam mutuamente) está presente tanto para o emissor como para o receptor. 
As produções midiáticas constituem, portanto, práticas sociais de caráter discursivo, construídas por um grupo social (os media), a partir da seleção e da reconfiguração de determinados repertórios. Portanto, o conteúdo apresentado pela mídia sobre uma organização define o que se fala, pensa e considera a seu respeito, influenciando determinantemente na relação entre a organização e o ambiente. A congruência entre o ambiente e o comportamento da organização é uma condição para que a empresa obtenha apoio societal (DOWLING; PFEFFER, 1975), enquanto a reputação é um recurso fundamental para ser legitimado pelo sistema (DIMAGGIO; POWELL, 1983). Bom exemplo encontra-se no artigo de Kjaergaard e Morsing (2006), no qual as autoras procederam a um estudo longitudinal em material publicado pela mídia de massa sobre a empresa Oticon A/S e analisaram quais as conseqüências para a reputação e a identidade organizacional da empresa dinamarquesa. As autoras concluem que a Oticon não é conhecida por seus produtos (aparelhos de audição), nem por seus lucros, mas sim por sua forte identidade, em grande parte construída pelo conteúdo das notícias, que em certo ponto tornaram-se fracamente relacionadas aos eventos reais envolvendo a própria empresa.

\section{Mídia e reconhecimento profissional}

Em pesquisas anteriores, Morin tratou amplamente da questão do sentido do trabalho para gestores franceses (MORIN, 1996) e para gestores e estudantes de administração quebequenses (MORIN, 2001). Apareceram respostas freqüentes do tipo: "um trabalho tem sentido se faz sentir-se útil, valorizado" (MORIN, 2001, p.15). Dejour (1993) já havia pontuado que o reconhecimento dos outros é um dos elementos fundamentais da construção da identidade do individuo, ocorrendo de modo dinâmico, a partir de suas interações sociais. Ele afirma que "no mundo subjetivo, o sentido dado ao trabalho depende de jogos de identidade e participação. O que o indivíduo espera do seu trabalho é também uma retribuição moral: o reconhecimento." Dejour fala ainda da atribuição de sentido à própria experiência de profissional pelos indivíduos e da importância do reconhecimento de utilidade; ou seja, utilidade social, econômica e técnica das contribuições particulares e coletivas à organização. As formas de reconhecimento no exercício da profissão são conferidas pela hierarquia, pelos pares ou pelo grupo social que influencia na motivação e autoconceito dos indivíduos (VASCONCELOS; VASCONCELOS, 2004).

Uma vez que aqui estamos tratando de gestores de serviços públicos, parece-nos pertinente considerar que a opinião pública (ou, no caso, a opinião pública quebequense) seja determinante do nível de auto-estima profissional dos executivos da RSSSQ. Vale ilustrar com um trecho da definição das atribuições dos cadres disponibilizada pela própria ACSSSS:

[....] responsabilidades principais [dos cadres] consiste em organizar, coordenar os recursos humanos materiais, de sistemas de informação e financeiros dos estabelecimentos de saúde e de serviços sociais [..] Os gestores devem zelar para que os recursos disponibilizados [da RSSSQ] sejam de ótima qualidade e em quantidade que atenda às necessidades da população quebequense, que tem este direito garantido por lei. (ASSOCIATION..., 2008, tradução nossa)

Há, portanto, coerência em relacionarmos reconhecimento profissional com opinião pública e com conteúdo da mídia de massa. A população quebequense "conhece" os executivos por meio das notícias, tornando-se coprodutora dos significados que estas apresentam. Em outras palavras, os executivos da RSSSQ, os media e a população quebequense formam um "triangulo de vozes" que participam da interanimação dialógica que constrói sentido sobre o trabalho, o desempenho e a atitude dos cadres na gestão do serviço público.Nesse sentido, não é de admirar que, quando indagados sobre práticas de reconhecimento que consideram importantes, os executivos tenham respondido que seu trabalho não é reconhecido pela população, acrescentando que as notícias dos jornais são um importante fator na construção de uma imagem que implica esse não-reconhecimento.

Partindo do pressuposto de que devemos levar em conta o conteúdo do que é veiculado na mídia para entender as origens dessa sensação de não-reconhecimento, analisaremos as notícias publicadas nos jornais 
quebequenses, visando identificar conteúdos relevantes no que diz respeito à atuação dos executivos da RSSSQ.

\section{Métodos}

Para entender como a mídia constrói sentido, é necessário analisá-la por um método que permita comparações sistemáticas e replicáveis. A análise de conteúdo clássica é bastante útil, pois decompõe os textos em códigos e explicita a lógica de encadeamento das idéias em um dado discurso (BARDIN, 1977). Ao aplicá-la a textos publicados em jornais, por exemplo, pode-se obter a interpretação do sentido conferido a um dado tema, a partir de uma sistemática de classificação e codificação. Autores como Krippendorf (1980) distinguiram estratégias distintas de pesquisa ao se valerem da análise de conteúdo, entre elas construir um corpus de texto como sistema aberto, a fim de verificar tendências e padrões de mudança. Essa foi nossa opção de estratégia de pesquisa.

O propósito de toda pesquisa qualitativa é produzir interpretação a partir de material que pode vir de diversas fontes: entrevistas, documentos, imagens, sons e textos. $\mathrm{O}$ ato de interpretar significa conceder significado segundo algum referencial.

No entanto, ocorre que a pesquisa social qualitativa enfrenta sempre grande dificuldade de legitimação. Bauer, Gaskell e Allum (2002) colocam que a dificuldade reside no uso de métodos que utilizam pouca formalização; ou seja, fica difícil avaliar a qualidade e a veracidade da interpretação. Por isso, é recomendável que a pesquisa social qualitativa utilize multimétodos, tentando produzir sentidos a partir dos fenômenos, em termos do que eles significam ou de como atingem a vida das pessoas. O pesquisador deve fazer uso de multimétodos, tornando a pesquisa social qualitativa uma atividade similar à bricolagem: pedaço por pedaço, várias técnicas misturadas para compor um quadro de leitura e interpretação do fenômeno social. (DENZIN; LINCOLN, 1994, p.3). Para ampliar a capacidade de produzir sentidos a partir do material coletado, procedemos a duas técnicas de pesquisa: a construção de um corpus de textos, seguido da análise dos seus conteúdos.

Um corpus de pesquisa pode ser definido como uma coleção de textos desenvolvidos a partir de um tema comum. Os sentidos mais recentes acentuam a natureza proposital da seleção, não apenas de textos, mas de qualquer material com funções simbólicas, como imagens, fotos e som . Neste artigo, analisamos um conjunto de notícias sobre o trabalho de executivos da RSSSQ, publicadas em 10 jornais da província de Québec no período de 1-1-1993 a 30-6-2003, totalizando 154 artigos. Tomamos o cuidado de pesquisar em todos os jornais representativos de Québec, não nos limitando apenas aos de grande circulação. Desse modo, também foram considerados aqueles de alcance regional. Os artigos em questão foram publicados nos seguintes periódicos: Le Soleil, Le Devoir, La Tribune, La Presse, La Voix de L'Est, Le Droit, Le Nouvelliste, Le Quotidien, Les Affaires e The Gazette.

\section{A construção do corpus de notícias dos jornais}

De acordo com Bauer e Aarts (2002), a construção de um corpus implica um método para escolha sistemática e seleção dos textos. Esse procedimento assemelha-se ao uso de amostras aleatórias na pesquisa quantitativa. Tanto a construção de corpus quanto a amostragem aleatória são funcionalmente equivalentes, pois garantem a eficiência que se ganha por triar algum material para caracterizar o todo. Evidentemente, são procedimentos com estruturas diferentes. $\mathrm{O}$ corpus tipifica atributos encontrados em uma população, sem, no entanto, proceder a nenhum tipo de generalização. Assim, a construção de um corpus de pesquisa é uma alternativa à amostragem estatística aleatória. Por sua vez, a amostra estatística tem representatividade inconteste, mas nem sempre é adequada para pesquisa com texto e imagem. É o caso, por exemplo, de análise de material publicado pela imprensa, eletrônica ou impressa. 
Em geral, aceita-se que o importante em um corpus é a representatividade e não o tamanho. Além disso, Barthes (1967 apud BAUER; AARTS, 2002, p.55) propõe que o material seja triado segundo critérios de relevância, de homogeneidade e de sincronicidade. O critério de relevância refere-se ao grau de notoriedade do material em termos da importância de seu acréscimo ao corpus. $\mathrm{O}$ de homogeneidade refere-se ao cuidado de não misturar materiais distintos, comprometendo a validade do sistema de codificação. Não se deve misturar imagem, texto e som, nem tampouco misturar textos em forma de artigos com entrevistas, por exemplo. Finalmente, a sincronicidade é o critério que garante que um corpus seja uma intersecção da história; ou seja, devem ser feitas coletas de material dentro de um ciclo de desenvolvimento de um tema, o que dá uma dimensão histórica à seleção.

Um corpus requer sucessivas correções, que devem ser implementadas a fim de compensar os vieses que vão sendo identificados. Pode-se dizer que um corpus está equilibrado quando esforços adicionais ao selecionar material não acrescentam novas categorias, nem implicam nenhuma revisão do critério de escolha. Isto é, novas escolhas terminam por classificar o artigo em categorias que já existem.

A construção do corpus de artigos dos jornais foi realizada selecionando-os a partir de um banco de dados eletrônico, o Eureka, disponível na biblioteca da HEC-Montréal. Tal banco possui apenas textos de jornais da imprensa quebequense. Naturalmente, o volume de artigos que identificamos cujo conteúdo tratava de algum assunto relacionado à RSSSQ era enorme. Por isso, foi necessário criar um procedimento de seleção, de análise preliminar, de validação e de confirmação do trabalho de interpretação do conteúdo das notícias. Começamos por proceder à seleção, utilizando palavras-chave. $\mathrm{O}$ total de artigos escolhidos para a análise foi resultado de uma série de rodadas de seleção. Após um número expressivo de rodadas, procedemos a uma análise de conteúdo preliminar. De posse dos resultados dessa primeira análise, um novo procedimento de seleção de artigos foi adotado para validar a análise inicial. Retiramos do Eureka todos os artigos de autoria de RicardChapelain Baptiste (R.C.B.), jornalista que assina uma coluna diária no jornal Le Soleil, dedicada a notícias sobre o sistema de saúde e serviço social de Québec. Nessa etapa de validação, apenas as colunas publicadas no ano de 2003 foram submetidas à análise de conteúdo em bases semelhantes à realizada inicialmente. A figura 1 ilustra o procedimento. 
Figura 1

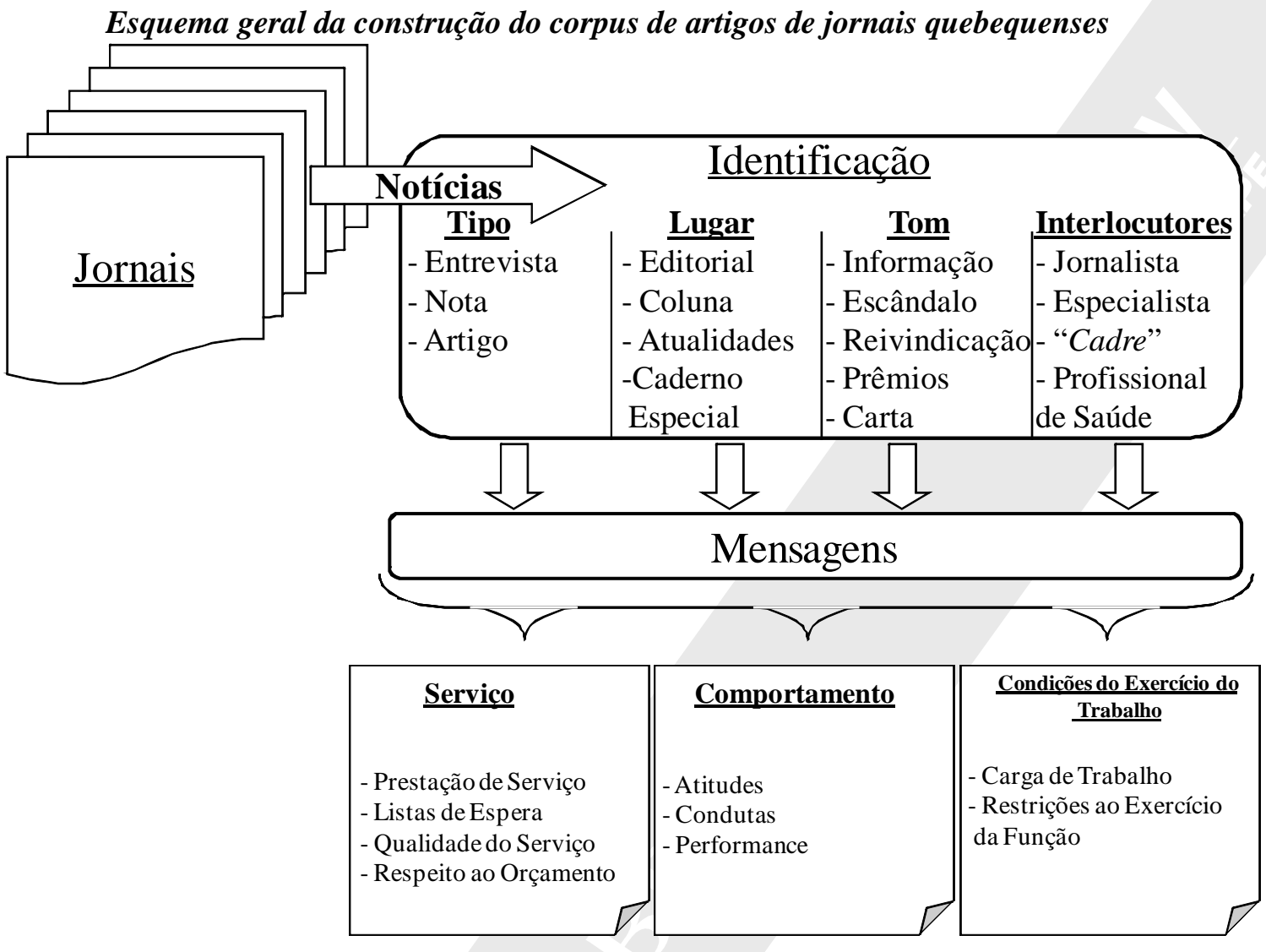

Fonte : Elaborado pelas autoras

Ainda com base em Bauer e Aarts (2002), a construção de um corpus de análise não busca o maior número de artigos, mas a maior abrangência de tipificações dentro das categorias de análise. Consideramos o fim das buscas por novos artigos no momento em que escolhas adicionais implicavam classificações semelhantes, sem acréscimos ou mudanças na interpretação da natureza do conteúdo.

Cabe também salientar que selecionamos artigos que aludissem especificamente ao trabalho dos executivos da RSSSQ. Por exemplo, não nos interessava analisar o conteúdo de todos os artigos sobre listas de espera em hospitais e centros de cirurgia, fazendo uma categorização de como o tema é tratado e apresentado à população. Os artigos tratando de listas de espera só foram considerados relevantes se oferecessem algum conteúdo sobre a atuação profissional, ação, atitude ou conduta dos executivos da RSSSQ. Esse procedimento de seleção nos mostrou que há imensa quantidade de notícias sobre a RSSSQ, mas pouco sobre o tema que procurávamos.

\section{Interação com o material empírico}

A tarefa mais complexa de qualquer análise de conteúdo é definir um procedimento de codificação e classificação em categorias dos textos do corpus constituído. Embora o corpus de texto esteja aberto a inúmeras questões possíveis, a análise interpreta o texto apenas à luz do referencial de codificação, que constitui uma seleção teórica que incorpora o objetivo da pesquisa (ver como exemplo STEMPEL, 1952). 
A interação com o material seguiu duas linhas diferentes de ação visando à classificação e à análise. A primeira se apoiou na identificação de características da notícia no jornal, como o lugar do artigo, o tipo de texto, o tom da notícia e o perfil do interlocutor ou autor do artigo (vocalidade). A segunda se pautou pela verificação de conteúdo, propriamente dita, com base em três categorias de codificação e análise, estabelecidas a partir de entrevistas com os executivos e que estão relatadas em Morin, Giroux e Pauchant (2001): serviços, comportamento e condições de trabalho.

\section{Lugar do artigo na publicação}

Esse item de análise identificou o lugar do artigo na publicação como revelador do nível de importância atribuído pelo jornal ao assunto abordado. Por exemplo, a disposição em cadernos ou em colunas especiais indica uma maior atenção com o tema. Nesse sentido, as classificações adotadas foram as seguintes:

- Caderno Especial: adendo esporádico ou freqüente. Por exemplo, na primeira semana de cada mês, no jornal Le Devoir, há o caderno Saúde;

- Coluna de Saúde: coluna especial do jornal para assuntos de saúde. Pode ter ou não frequiência definida e autor específico;

- Editorial: espaço reservado à opinião do(s) editor(es). Em boa medida, revela a orientação ideológica da própria publicação;

- Atualidades: matéria comum, sem destaque ou lugar especial;

- Rapport (Informativo): texto publicado sob encomenda de alguém ou de instituição específica. Por exemplo, relatórios anuais do Ministério da Saúde e Serviços Sociais do Québec.

\section{Tipo de texto}

Análise sobre o formato básico do texto. Analogamente ao item anterior, o tipo de artigo denota a importância que a jornal atribui ao tema. Vale a pena verificar se o assunto merece o destaque de uma entrevista ou uma simples nota (texto pequeno). As classificações foram: entrevista, nota, artigo (texto assinado por jornalista) ou carta (de leitor).

\section{Tom}

Expressão de ênfase ou drama, assumida pelo texto ao tratar a notícia. As classificações foram: informação (tom brando, com sentido de esclarecimento), condenação (tom severo, em forma de reprovação ou de repreensão), reivindicação (tom severo, requisitando algo de direito que não está sendo respeitado), reconhecimento (especificamente relacionado à concessão de prêmios) e escândalo (tom negativo, severo e de evidente reprovação a algum ato, evento ou à conduta de alguém).

\section{Interlocutor}

Identifica o ator emissor (escritor) da mensagem. O objetivo é identificar no conteúdo as características do emissor, seu grau de conhecimento, legitimidade, projeção e envolvimento com a RSSSQ. As categorias utilizadas foram: especialista (personagem externa à RSSSQ, porém com notável conhecimento sobre saúde e serviços sociais em Québec), profissional de saúde ou serviço social, população em geral, jornalista e executivos (quando o emissor era um cadre). 


\section{Mensagem}

Como mencionado, as categorias para análise do conteúdo das matérias foram definidas pelos próprios executivos, conforme Morin, Giroux e Pauchant (2001). Foram elas: serviços, comportamento e condições de exercício do trabalho.

A categoria Serviços foi definida como aquela que englobaria textos cujo conteúdo versasse sobre prestação de serviços, incluindo eventos, conflitos, mudanças, explicações ou qualquer sorte de notícias que relatassem a atuação dos executivos na gestão dos serviços. Ela incluiu subcategorias, num esforço para tornar mais clara a codificação. Foram elas:

- prestação de serviços - notícias relatando participação ou omissão de executivos da RSSSQ na gestão dos serviços;

- lista de espera - notícias nas quais se identificasse a posição ou a ação dos executivos quanto às longas listas de espera por serviços da RSSSQ (por exemplo, filas para cirurgias cardíacas ou para realização de exames de ressonância magnética);

- qualidade dos serviços - notícias sobre a qualidade dos serviços, com respeito ao papel, à ação ou à omissão dos executivos;

- respeito ao orçamento - implicações da lei de orçamento da província de Québec (aprovada em 2001) para o trabalho dos executivos.

Na categoria Comportamento, foram colocados textos que tratassem da ação ou atitude dos executivos. As subcategorias foram: atitude - ação deliberada com um propósito; condutas - enunciado sobre postura ética em situação de conflito, crise ou impasse e performance - textos relatando abertamente questões de desempenho, com ou sem êxito. Ao longo do estudo, optamos por classificar nessa subcategoria textos relatando concessão de prêmios por mérito e outros tipos de homenagens aos executivos da RSSSQ.

Finalmente, as notícias sobre condições de trabalho também foram classificadas numa categoria própria, dividida em duas: volume de trabalho, especificando a quantidade e a abrangência deste, e restrições, englobando textos com situações específicas ou obstáculos a sua realização.

\section{Resultados}

A mídia impressa auxilia na construção de uma imagem por meio da combinação de recursos como o lugar da notícia no jornal, o tipo de texto, o tom, a interlocução e o conteúdo da mensagem. O resultado da análise de conteúdo das notícias dos jornais sugere que os executivos da RSSSQ não conseguiram atingir resultados satisfatórios por conta de restrições do próprio sistema, sejam orçamentárias ou operacionais. Além disso, nos jornais, eles aparecem como um recurso que a RSSSQ precisa alocar, cortar e usar de forma eficiente. Por último, concluímos que as notícias os retratam em posição reivindicatória, seja por melhores condições de trabalho, seja por isonomia salarial ou por direito a bonificações e benefícios concedidos a executivos de outros ministérios.

Quanto ao lugar, a quase totalidade dos artigos está disposta em colunas gerais, em meio a notícias cotidianas, no que denominamos Atualidades. Há alguns artigos na categoria Editorial, expressando a opinião dos editores do jornal, geralmente, em tom de reprovação.

Quanto ao tipo, a maior parte dos textos está na forma de artigos. Em seguida, aparecem as notas, reportando a concessão de prêmios e reconhecimentos dentro das próprias associações de classe dos executivos, tal como a ACSSSS. Aqui, cabe ressaltar que houve a identificação de apenas uma entrevista concedida por um executivo, ex-ministro. Tal fato suscita a discussão sobre o porquê dos executivos não terem voz na imprensa. Já que a gestão da saúde e dos serviços sociais é um tema tão relevante e presente nos jornais, por que os próprios 
executivos não são entrevistados para que mostrem seu trabalho? Isso reforça a idéia de que as notícias sobre a RSSSQ são, em geral, focadas em escândalos, em falhas e no relato de problemas. A pouca utilização dos jornais pelos próprios executivo resulta num limitado espaço para a legitimação e a produção de sentidos que lhes sejam positivos.

O tom de indignação apareceu, sobretudo, nas entrevistas ou depoimentos do presidente da associação de executivos da RSSSQ, Robert Savard. Suas declarações versavam sobre discrepâncias entre programas de bonificação de um ministério para outro, além de reivindicações quanto a remuneração e benefícios. $\mathrm{O}$ tom condenatório era ainda mais marcante nas colunas de Ricard Châtelein-Baptiste. O uso constante de algumas expressões como "vítimas das escolhas do governo" e "estado de penúria" reforçam uma imagem negativa do trabalho dos executivos. A RSSSQ é retratada como um ambiente no qual as ações são desarticuladas, cheia de restrições, estando os executivos à mercê da vontade política do governo, dos estrangulamentos conjunturais ou da lei que regula o orçamento da província.

Tratando agora do conteúdo das mensagens nas notícias em si, os resultados serão apresentados nas subcategorias de cada uma das três categorias escolhidas pelos próprios executivos: serviços, comportamento e condições de exercício do trabalho.

A categoria Serviços é composta das subcategorias prestação de serviços, lista de espera, qualidade do serviço e respeito ao orçamento. Na prestação de serviços, foram colocados textos nos quais estivessem retratadas situações sobre a evolução dos serviços, em termos de processos e de envolvimentos dos executivos, identificando práticas discursivas de sentido positivo ou negativo com a forma como os serviços são disponibilizados pela RSSSQ. As análises nos fizeram concluir que o desenrolar das atividades de prestação de serviços têm espaço no jornal ao relatarem conflito, desentendimento, tensão ou crise.

Fonte: Le Devoir (4-11-1993)

Título: "Visitas médicas racionadas?"1

Trecho: [depoimento de um executivo] Somos requisitados a oferecer a mesma qualidade de serviços de sempre, mas a Rede aumentou muito o número de atendimentos, acolhendo cada vez mais clientes... Precisamos explicar à população que não podemos fazer tudo, que não podemos mais cortar (despesas) sem cessar serviços. Além disso, temos que aumentar, a qualquer preço, nossa produtividade [depoimento de diretora do Hospital de Notre Dame, Montreal]. Se o governo quer um retorno financeiro imediato, deverá esclarecer à população quantos leitos terão de ser retirados, quantas consultas serão diminuídas e quantas cirurgias serão postergadas.

Fonte: La Presse (15-1-1999)

Título: "O clima de trabalho deixa a desejar na CSST"2

Trecho: [depoimento do diretor da CSST, sobre clima organizacional ruim e realocação de alguns executivos] "é bom que alguns cadres tomem um pouco de ar. Ao mudarmos o mal de lugar, nós conseguiremos reanimar as pessoas".

Quanto às listas de espera, são insistentemente mostradas como o resultado do envelhecimento da população, do aumento dos custos dos fornecedores e, paralelamente, uma decorrência da necessidade de se obedecer à lei de equilíbrio fiscal, promulgada em Québec a partir de 2000. Portanto, ao tratar do problema das listas, muitas vezes, as notícias referem-se aos executivos como um recurso que onera o orçamento e, em conseqüência, implica redução de outros recursos necessários, acarretando o aumento das listas de espera. Em outras palavras, os textos tratam os profissionais como mais um recurso que compete no orçamento, o que reforça a escassez e, portanto, ajuda a "aumentar as listas". A análise do tema das listas revela uma imagem de recurso que pode ser 
diminuído, aumentado ou alocado em função de decisões gerenciais. As listas apareceram freqüentemente como função do estrangulamento causado pelos altos custos com a própria gestão da RSSSQ, sendo os executivos o recurso mais caro e de difícil alocação.

Fonte: L'Actualité (15-3-1994)

Título: "Déficit: indignação contra o desperdício"”

Trecho: A população envelhece e a demanda [por serviços de saúde e bem-estar] aumenta. Nós decidimos colocar uma rolha nisso! Doentes ou sãs, as pessoas vão ter que conviver com essa rolha. $O$ que transborda vai ter que esperar. Foi assim que criamos as listas de espera.

Fonte: Quotidien (23-10-1998)

Título: "Estabelecimentos de saúde: o déficit se eleva a quase 14 milhões" 4

Trecho: Com um déficit que beira os 14 milhões nos estabelecimentos de saúde da [região] SaguenayLac-Saint-Jean, a margem de manobra da Rede será bastante restrita nos próximos anos [...] [A] lista de espera de pessoas que precisam de um lugar em abrigos e cuidados de longa duração foi consideravelmente reduzida, sem que o número de leitos fosse aumentado. Na verdade, o número de leitos vem diminuindo. A Rede contava com 40 estabelecimentos na região. Hoje, não conta nem com $14[\ldots]$.

Quanto à qualidade dos serviços prestados, os textos revelaram que a imagem dos executivos é relacionada a impotência e ausência de resultados, malgrado os esforços em contrário. As notícias estão centradas nos problemas referentes à manutenção do nível de qualidade dos serviços prestados e nas restrições à ação dos executivos. Uma vez que não há textos na forma de entrevistas ou em cadernos especiais, falta um espaço onde os executivos possam expor seus planos de trabalho e as ações voltadas para a solução dos problemas, a despeito da escassez de recursos. Portanto, na coluna Atualidades, a qualidade dos serviços prestados é sempre vista do ponto de vista do jornalista, denotando uma situação problemática.

Fonte: Le Droit (21-12-1994)

Título: "Relatório sobre o Pavilhão do Parque"5

Trecho 2: Eu [profissional do Ministério] fiquei assustado ao constatar que as salas do edifício estão sempre com todas as portas trancadas; os beneficiários não podem circular livremente, os corredores têm grades e exposição contínua ao sol, apesar dos esforços recentes, muitos beneficiários não tem atividades durante o dia.

Fonte: Le Soleil (5-4-2003), coluna de Ricard-Châtelain Baptiste.

Título: "Sistema de saúde: os recém nascidos custarão caro"6

Trecho: Não há o que fazer, a não ser reinvestir na Rede, a fim de recuperar (rehausser) a qualidade dos serviços [...] pois o subfinanciamento afetou significativamente a saúde [afirma um executivo, diretor de hospital].

Quanto ao respeito ao orçamento, a ação dos executivos é quase sempre vinculada a desentendimentos em razão da necessidade de se ater aos limites impostos. Tais limites orçamentários geram mais restrições à alocação de recursos, já escassos por causa do excesso de pessoal na RSSSQ, do envelhecimento da população 
e do aumento das despesas com fornecedores. Essas restrições resultam em listas de espera e no comprometimento da qualidade dos serviços, motivando brigas por recursos. Nessa linha de raciocínio, os executivos se veriam impotentes, aparecendo praticamente como vítimas da lei orçamentária, advindo daí a idéia de que são obrigados a fazer o que não querem, por força da lei.

Como se vê, a crise econômica do setor de saúde requer a alocação de recursos e o condicionamento à lei de equilíbrio fiscal. Nesse sentido, além de serem vistos como um recurso a "utilizar" (os verbos usados são "cortar", "realocar", "usar", "transferir" e "remanejar", entre outros de sentido análogo), os executivo são igualmente apresentados como indivíduos que nada podem fazer diante dos problemas, pois têm de "obedecer" (outros verbos empregados são "observar", "respeitar" e "ater-se", entre outros).

Fonte: Le Soleil (19-3-1997)

Título: "Os cortes previstos já chegaram" 7

Trecho: Mesmo os profissionais sindicalizados do Estado não serão poupados. Com efeito, os executivos (cadres), os juízes, os deputados, os ministros e os políticos, em geral, passarão por contenções [salariais] da ordem de 300 milhões de dólares [canadenses] do total gasto com remuneração [...] A redução de 831,7 milhões [dólares canadenses] na massa salarial [...] se fará sentir principalmente na Rede de Saúde e de Educação.

Fonte: Le Soleil (28-10-2001)

Título: "Corte na saúde: o Centro Mitissiano está farto! Estrangulado por um déficit de 400.000\$, lança um apelo ao público"s

Trecho: Nós [executivos] vivemos um contra-senso. Québec nos dá missões na saúde a cumprir, mas há uma lei que nos obriga a manter um equilíbrio orçamentário. Para nós, são decisões muito difíceis de serem tomadas.

Fonte: Le Soleil (3-7-2003), coluna de Ricard-Châtelain Baptiste.

Título: "Fim dos nascimentos no [hospital] Saint-Sacrement"

Trecho 1: "Vítima" das decisões do governo, o diretor geral do CHA [hospital] [...] caiu [ao saber que o ministro da saúde cortara recursos para obstetrícia] [...] O diretor declarou: "nós estamos tristes com esta bagunça [...] Ninguém nos escuta [...]”.

A categoria comportamento foi dividida em atitudes, conduta e performance. Dois tipos de condutas foram mais freqüentemente relatados. Em primeiro lugar, conflitos entre os próprios gestores ou entres estes e autoridades como o ministro, envolvendo disputas, desacordos e situações de extremo confronto.

Fonte: La Presse (15-01-1999)

Título: “O clima de trabalho deixa a desejar na CSST"10

Trecho 2: Os resultados da pesquisa de clima organizacional revelam julgamentos particularmente severos no que tange à confiança em relação aos superiores. Uma minoria acredita que seja realmente possivel identificar meios concretos para melhorar seu rendimento com apoio de seus superiores. 
Fonte: Le Soleil (4-6-2003), coluna de Ricard-Châtelain Baptiste.

Título: "Vários hospitais descumprem a lei" "11

Trecho: Vários hospitais do Québec, se não a maior parte, não cumprem a lei de proteção das informações pessoais, solicitando doações a seus ex-pacientes [...] Após o término de sua estadia, o cliente recebe uma carta da direção-geral [exercida por cadres], assinada pelo próprio diretor-geral [...] solicitando uma contribuição ao hospital.

Fonte: Le Soleil (3-7-2003), coluna de Ricard-Châtelain Baptiste.

Título: "Fim dos nascimentos no [hospital] Saint-Sacrement"

Trecho: O ministro [em resposta às queixas dos executivos por causa dos cortes], afirmou "faltam aos dirigentes regionais [da RSSSQ] competências de liderança [...] [O] ministro não pode resolver tudo no Québec".

Isso corrobora as interpretações da categoria "serviço", conforme já apresentado anteriormente. Em segundo lugar, encontramos notícias cujos termos acabam por caracterizar os executivos como profissionais insatisfeitos e em posição defensiva, reagindo com energia, impaciência e até agressividade ao que se passa dentro da RSSSQ.

Fonte: Le Soleil, 8-2-1997

Título: "Executivos furiosos"12

Fonte: La Presse, 18-3-1997

Título: "Executivos do governo cerram fileiras"13

Trecho: Considerando enfrentar as contenções orçamentárias anunciadas, os executivos do governo estão descontentes [...] Os cadres [...] se reorganizaram em uma única associação que pretende representá-los, com mais de 25.000 membros.

Quanto à conduta, os artigos relatam situações sempre em tom de condenação, destacando as restrições ou a desmotivação, o que reforça a imagem de insatisfação e posição defensiva. Além disso, há relatos em tom de indignação, seja retratando algum incidente que envolva falta de transparência, seja denotando má conduta por parte dos gestores.

Fonte: Le Droit (21-12-1994)

Título: "Relatório sobre o Pavilhão do Parque"

Trecho: O relatório [do profissional do Ministério da Saúde] condena a autoridade exercida pelos pais [das crianças assistidas no pavilhão] que exercem sobre os cadres uma verdadeira autoridade patronal, fazendo-os comparecer diante do conselho de administração [do Parque] para explicar cada uma de suas decisões.

Quanto à performance, essa categoria mereceu artigos que tratavam de alguma forma da questão do desempenho geral dos executivos da RSSSQ. Entretanto, verificamos que poucos artigos abordavam diretamente seu esforço por maiores possibilidades de alcançar resultados ou objetivos. Só identificamos conteúdo que trata do trabalho dos executivos em si quando a notícia versa sobre a concessão de prêmios, em 
geral, pelas suas próprias associações de representação. Há, também, notícias sobre as concessões de prêmios e de bônus. Nesse caso, os artigos mostram as controvérsias entre os próprios executivos da RSSSQ sobre se a distribuição de bônus deveria ou não ser somada ao salário. Desse modo, mais uma vez, os cadres aparecem nos jornais em situações de conflito e de controvérsia, acrescentando-se que não há um esclarecimento sobre a natureza da execução das tarefas, sobre planejamento ou qualquer indicativo de como é conduzida a gestão da RSSSQ.

Fonte: Le Soleil (7-7-1996)

Título: "Estado limpa as gavetas"14.

Trecho: Os executivos estão furiosos com um possível impedimento a sua progressão salarial [...] Em tempos de crise orçamentária [...] o Estado considera a hipótese de congelar seus salários.

Fonte: Le Nouvelliste (13-3-2002)

Título: "Confronto no CLSC Les Forges"

Trecho: O conselho de administração do CLSC teve uma sessão bastante conturbada ontem, marcada por trocas de ofensas entre o novo presidente do conselho e o ex-presidente, demissionário. $O$ presidente explicou que o conselho havia confiado no ex-presidente [...], porém ele retorquiu que sempre fora contra a decisão do conselho em favor das listas de espera.

A categoria Condições de Exercício do Trabalho foi subdividida em carga de trabalho e restrições ao exercício da função. Aqui, destacamos um ponto curioso. Como já foi explicado, as três categorias foram escolhidas durante entrevistas e interações com os executivos (MORIN; GIROUX; PAUCHANT, 2001. Pareceu-nos natural supor que eles as propuseram a partir de seu ponto do vista sobre o assunto, que implicava considerar que vinham enfrentando um aumento significativo da carga de trabalho, por conta da situação de crise na Rede, das restrições (e reduções) ao uso de recursos e da redução no número de executivos. Portanto, tratar de carga de trabalho e restrições ao exercício da função lhes parecia um conteúdo pertinente para investigação. Contudo, a pesquisa com os textos mostrou-nos uma condição um tanto diferente. As notícias não tratavam diretamente da carga de trabalho dos executivos, considerando-a alta ou baixa. Não encontramos conteúdo voltado para isso, a não ser quando os próprios cadres eram os interlocutores, como é o caso de notas através das quais Robert Savard se pronunciava, em tom queixoso e reivindicativo, a respeito do aumento de trabalho, sem correspondente aumento de remuneração. Por exemplo:

Fonte: Le Devoir (1-5-1993).

Título: "Os gestores [cadres] em busca de reconhecimento e respeito" 16

Trecho: Exercendo uma função de pouca visibilidade perante a opinião pública, os cadres ressentemse, mais do nunca, de não estarem unidos pela melhoria de sua imagem e para fazerem valer seus direitos.

Fonte: Le Soleil (28-10-2001)

Título: "Corte na saúde, o Centro Mitissiano está farto! Estrangulado por um déficit de 400.000\$, lança um apelo ao público".

Trecho: Nós passamos de 64 para 22 executivos com a reforma [em 2000]. As novas regras são tão severas, que ninguém se conhece mais aqui. 
Fonte: Le Soleil (5-4-2003), coluna de Ricard-Châtelain Baptiste.

Título: "Sistema de saúde: os recém nascidos custarão caro"17

Trecho: Segundo a diretora do Instituto [...], o envelhecimento da população e a projeção do uso de serviços de saúde está equivocada [...] "há interesses na privatização [do sistema de saúde]" [...] [A] diretora quer o fechamento das clínicas privadas de Québec [...], pois no atual estado de penúria, o único resultado será a perda dos profissionais para a iniciativa privada.

No mais, o corpus de notícias analisados não nos permitiu concluir que o que se leu nos jornais sobre os cadres levaria a população a construir uma imagem de que estes estivessem particularmente "sobrecarregados". No que diz respeito às condições de trabalho, os conteúdos trazem a idéia de luta por melhorias.

Quanto ao exercício da função, foi interessante constatar que esse tema já fora abordado na categoria Serviços, na qual as notícias falam das restrições a esse exercício como conseqüência da necessidade de se respeitar o orçamento da província. Nesse sentido, cogitamos a hipótese de que a escolha dessa categoria pudesse estar relacionada a restrições de outra natureza, além da orçamentária, mas as notícias não aludiram a nenhum conteúdo específico. Assim, continuamos a ver os executivos da RSSSQ como profissionais que enfrentam uma situação de escassez, obrigados a fazer opções quando da alocação de recursos, sob o imperativo da obediência às determinações da lei orçamentária de Québec. Além disso, encontramos conteúdo no qual o que se manifesta é a indignação diante, por exemplo, das dificuldades de associação e de mobilização.

Fonte: Le Devoir (1-10-1994)

Título: "Executivos dos setores público e privado querem poder negociar condições de trabalho" 18

Trecho: Perto de 20.000 membros da Confederação Nacional de Executivos do Québec reivindicam que o governo promova uma emenda ao Código do Trabalho que lhes permita negociar suas condições [...] Segundo Robert Savard, a América do Norte é o único continente do mundo que não reconhece o direito dos executivos se organizarem (ou se associarem) [...]. Um compromisso que nem os governantes, nem as empresas privadas do Canadá respeitam.

Fonte: Le Droit, 1-5-2001 (Editorial)

Título: "Cifras surpreendentes"19

Trecho: Não há bons políticos sem bons gestores [públicos]. A população não sabe o que os políticos municipais devem aos funcionários do município [...]A insuficiência [de gestores públicos] é uma questão resolvida por sindicalistas, não pelo próprio contribuinte, que é quem deve mandar, tanto nos gestores como nos políticos [...]. O contribuinte precisa começar a se importar com a forma como são tratados os gestores públicos ou a qualidade dos serviços vai cair muito.

As análises dos artigos dos jornais de Québec, feitas com os recursos da construção de um corpus de textos e do uso de análise de conteúdo, permitiu-nos um conjunto de conclusões melhor delineado, feito a partir das sucessivas etapas de escolha, de classificação e de análise.

A formação de uma imagem negativa perante a opinião pública foi uma das consequiências dessas notícias, provocando nos executivos da RSSSQ um sentimento de não-reconhecimento profissional que levou ao burnout e ao esgotamento psíquico. Decididamente, os jornais contribuíram para criar um sentido negativo no que 
tange à atuação, à conduta e à performance desses profissionais. A análise desse noticiário revelou que a imagem do desempenho dos executivos da RSSSQ pode ser relacionada aos seguintes termos:

- Vítima: essa imagem está presente na ênfase dada às narrações sobre a obrigação de devolver fundos ao ministério (mesmo com a escassez de recursos e as listas de espera por serviços), nas situações de conflito com autoridades pela alocação de recursos e na permanente utilização da palavra penúria para referir-se a atual situação do trabalho desses profissionais.

- Recurso: os executivos são frequientemente tratados com um recurso. Nessa condição podem "estar em falta", "estar mal alocados", "ser a causa do mau funcionamento da máquina" ou "podem ser remanejados". Enfim, estão sujeitos a todo tipo de ação realizada com equipamentos ou máquinas. Nesses casos, o discurso se desumaniza e esses profissionais são vistos como algo que absorve outros recursos, sem que, necessariamente haja um retorno para o ambiente profissional em termos de eficiência.

- Reinvindicação: os executivos aparecem constantemente retratados pela voz do presidente de suas federações ou associações de classe. Os depoimentos são sempre inflamados, com forte tom de indignação, de ameaça (de greve ou de colapso nos serviços da Rede) e de insatisfação com a situação geral. Os termos empregados no noticiário são, inclusive, entes reforçadores dessa imagem de "monstro", valendo-se de expressões como "mostrar os dentes".

\section{Conclusão}

A mídia se constitui numa prática discursiva, dado que é a interpretação do público que lhe dá sentido. Portanto, a análise do material midiático deve ser uma análise discursiva, ou seja, com foco na linguagem empregada, reconhecendo a importância desta para promover a ação humana (SPINK; FREZZA, 2000). Em outras palavras, o conteúdo dos artigos publicados sobre um tema dá idéia do que se pode esperar dos leitores como reação. A criação de sentido, visto como uma construção social, é um empreendimento coletivo e interativo por meio do qual as pessoas constroem os termos pelos quais interpretam, compreendem e lidam com as situações e os fenômenos a sua volta.

Esta pesquisa mostrou que os gestores ou executivos da Rede de Saúde e de Serviços Sociais do Québec têm razão quando não se sentem reconhecidos pela população, por causa da imagem negativa ou depreciativa com que são mostrados pela imprensa local.

A análise de conteúdo de um corpus de artigos publicados em 10 jornais quebequenses no período 1993-2003 revelou que o modo como os executivos do RSSSQ são retratados leva os leitores a vê-los como vítimas da crise no sistema público de saúde ou como um recurso que precisa ser alocado, realocado, reduzido ou mesmo cortado. Muitas vezes, também são tidos como profissionais do serviço público que só recorrem à mídia para reclamar de salário, bônus e de outras questões relacionadas à remuneração. É raro os cadres aparecerem na imprensa falando da natureza de seu trabalho e de iniciativas que adotem para superar a crise na saúde e nos serviços sociais da província de Québec. Esses executivos seriam meros atores citados nos relatos sobre os problemas nas organizações formadores do RSSSQ. Por conseguinte, não causam surpresa as reclamações desses profissionais de que não são reconhecidos e os efeitos daí advindos no que diz respeito a problemas de saúde e de comprometimento da qualidade de vida no ambiente de trabalho.

No noticiário jornalístico examinado, não encontramos informações sobre o que fazem esses executivos, quais suas responsabilidades, nem como administram a RSSSQ em tempos de crise. Pelo que foi publicado, a população não tem como realmente conhecer a trabalho desses servidores públicos.

Não se deve esquecer, no entanto, que a notícia não se produz sozinha e que a comunicação é sempre um caminho múltiplo. Assim, para fins práticos, sugerimos que esses profissionais, a partir dessas constatações, desenvolvam um trabalho de aproximação dos jornais, tornado-se uma fonte de informação sobre questões 
relacionadas a saúde e serviço social e não, simplesmente, "fornecedores de eventos bárbaros" para criar notícias jocosas. Essa é a primeira proposição deste estudo

Além disso, recomendamos o desenvolvimento de uma política de comunicação em que todos os públicos relevantes sejam contemplados com veículos, mensagens e freqüência adequadas, fazendo jus à importância de seu papel na sociedade quebequense.

As crises no sistema de saúde do Brasil podem trazer conseqüências semelhantes e, portanto, é interessante atentar para a prevenção e a preservação dos bons profissionais do campo.

Acreditamos que caso adote essas proposições preliminares, a Rede de Saúde e Serviços Sociais do Québec restabelecerá os sentidos do trabalho para seus executivos, contribuindo assim para uma melhor qualidade de vida, um aspecto relevante tanto para a eficiência da organização, quanto para a saúde física e psíquica de seus profissionais.

Adicionalmente, ao adotar essas proposições preliminares, a Rede de Saúde e Serviços Sociais do Québec iniciará um processo de restabelecimento dos sentidos do trabalho para seus executivos, o que contribuirá para uma melhor qualidade de vida; aspecto relevante tanto para a eficiência da organização, quanto para a saúde física e psíquica de seus profissionais. 


\section{Referências}

ASSOCIATION DES CADRES SUPÉRIEURS DE LA SANTÉ ET DES SERVICES SOCIAUX. Disponível em: < http://www.acssss.qc.ca>. Acesso em: 16 out. 2008.

ATKINS, S.; CLEAR J.; OSTLER, N. Corpus design criteria Literary and Linguistic Computing, v.7, n.1, 1992.

BARDIN, L. Análise de conteúdo. Lisboa: Edições 70, 1977.

BAUER, M. The medicalization of science news - from the "rocket-scalpel" to the "gene-meteorite" complex. Social Science Information, v. 37, n. 4, p. 731-751. 1998.

BAUER, M. W.; AARTS, B. A construção do corpus. um princípio para coleta de dados qualitativos. In: GASKELL, G.

Pesquisa qualitativa com texto imagem e som: um manual prático. Petrópolis: Editora Vozes, 2002. p.15-36.

; ALLUM, N. Qualidade, quantidade e interesses do conhecimento evitando confusões. In:

GASKELL, G. Pesquisa qualitativa com texto imagem e som. Petrópolis: Editora Vozes, 2002. p.15-36.

CANADÁ. Ministère de La Santé et des Services Sociaux Québec. Le Système de Santé et de Services Sociaux au Québec, en bref. Disponível em: <http://www.msss.gouv.qc.ca/sujets/organisation/ssss_enbref>. Acesso em: 16. out. 2008.

CASTELLS, M. A galáxia da internet. Rio de Janeiro: Jorge Zahar, 2003.

CHOMSKY, N.; HERMAN, E. Manufacturing consent: the political economy of mass media. New York: Pantheon Books, 1988.

DEJOURS, C. Intelligence pratique et sagesse pratique: deux dimensions méconnues du travail réel. Education Permanente, n.116, 1993.

DENZIN, N. K.; LINCOLN, Y. S. Handbook of qualitative research. London, UK: Sage Publications Inc, 1994.

DIMAGGIO, P. J.; POWELL, W. W. The iron cage revisited: institutional isomorphism and collective rationality in organizational fields. American Sociological Review, v.48, n.2, p.147-160, 1983.

DOWLING, J.; PFEFFER, J. Organizational legitimacy: social values and organizational behavior. Pacific Sociological Review, v.18, n.1, p.122-136, 1975.

KJAERGAARD, A.; MORSING, M. Seized by the media: an empirical study of media influence on identity dynamics. Artigo apresentado ao EGOS Colloquium 2006.

KRIPPENDORF, K. Content analysis: an introduction to its methodology. London: Sage, 1980.

MEDRADO, B. Textos em cena: a mídia como prática discursiva. In: SPINK, M. J. (Org.). Práticas discursivas e produção de sentidos no cotidiano: aproximações teóricas e metodológicas. São Paulo: Cortez Editora, 2000.

MORIN, E.. L'Efficacité organisationnelle et le sens du travail. In: PAUCHANT, T. C. et al (cords.) La quête du sens: gérer nos organizations pour la santé des personnes de nos societés et de la nature. Québec; Editions de l'organisation, 1996. (Collection Manpower. P.257-286)

MORIN, E.; GIROUX, H.; PAUCHANT, T. Project Qualité de Vie au Travail. Interventions et budget; Montréal: HECMontréal, 2001.

MORIN, Estelle M Os sentidos do trabalho. RAE Revista de Administração de Empresas. Fundação Getúlio Vargas-SP, v. 41, n. 3, p. 8-19. 2001.

O'Shaughnessy, J.; O'Shaughnessy, N. The undermining of beliefs in the autonomy and rationality of consumers. London, UK: Routledge, 2007. 
SILVERSTONE, R. Why study the media. London: Sage, 1999.

SPINK, M. J.; FREZZA, R. M. Práticas discursivas e produção de sentidos: a perspectiva da psicologia social. In:

(Org.). Práticas discursivas e produção de sentidos no cotidiano: aproximações teóricas e metodológicas. São Paulo: Cortez Editora, 2000.

; MEDRADO, B. Produção de sentidos no cotidiano: uma abordagem teórico-metodológica para análise das práticas discursivas. In: Práticas discursivas e produção de sentidos no cotidiano: aproximações teóricas e metodológicas. São Paulo: Cortez Editora, 2000.

STEMPEL, G. H. Sample size for classifying subject matter in Dailies: research in brief. Journalism Quarterly, v.29, p.321322, 1952.

THOMPSON, J. Ideologia e cultura moderna. Petrópolis: Vozes, 1995a.

VASCONCELOS, F.; VASCONCELOS, I. Identidade e mudança: o passado como ativo estratégico In: . (Org.).

Paradoxos organizacionais: uma visão transfo

1 "Les visites médicales rationnées?", no original em francês.

2 "Le climat de travail laisse à désirer à la CSST". A notícia trata dos resultados de uma pesquisa de clima realizada num dos principais órgãos governamentais, a Comission de la Santé et de la Securité du Travail. Depois dessa pesquisa, houve mudanças nos quadros de direção e a implantação de programas de treinamento para os executivos.

3 "Déficit: haro sur le gaspillage". Trata-se de uma das poucas entrevistas que encontramos, na qual o ex ministro da Saúde Yves Séguin fala do trabalho na RSSSQ e acusa o governo da época de desperdício e má gestão, o que acarretaria listas de espera.

4 "Etablissements de santé. le déficit s'elève à près de 14 million \$".

5 "Rapport sur le Pavillon du Parc". A notícia refere-se ao trabalho de um funcionário do Ministério da Saúde ao avaliar o funcionamento de uma casa para estadias de longa duração para indivíduos com limitada capacidade intelectual, chamada Pavillon du Parc d'Aylmer.

6 "Système santé. les aînés coûteront moins cher qu'on le dit, selon um expert".

7 "Le coupes prévues sont au rendez-vous".

8 "Coupes santés: le centre mitissien en a assez". A notícia refere-se ao centro da RSSSQ em La Mitis, municipalidade que pertence à região de Bas-Saint-Laurant.

9 "Fini les naissances à Saint-Sacrement, tranche Couillard". O então ministro da Saúde, Phillippe Couillard, anuncia cortes em serviços especializados, tal como o fim da realização de partos no Hospital Saint-Sacrement et Enfant-Jésus, na cidade de Québec.

10 "Le climat de travail laisse à désirer à la CSST". A notícia trata dos resultados de uma pesquisa de clima realizada num dos principais órgãos governamentais, a Comission de la Santé et de la Securité du Travail, depois da qual houve mudanças nos quadros de direção, além de iniciativas de treinamento.

11 "Plusiers hopitaux enfreignent la loi".

12 "Cadres em furie". Executivos em fúria com a perspectiva de enquadramento salarial num nível abaixo do esperado.

13 "Les cadres du gouvernement montrent les dents".

14 "L'État grate les fonds de tiroirs".

15 "Affrontement au CLSC Les Forges". A notícia trata do desentendimento entre executivos do conselho de administração do Centre Local de Services Communautaires, que oferece serviços de saúde preventiva, curativa, de readaptação e de reinserção social.

16 "Les cadres em quête de reconnaissance et de respect".

17 "Système santé. les aînés coûteront moins cher qu'on le dit, selon um expert".

18 "Le cadres du prive et du public veulent leurs conditions de travail".

19 "Des chiffres étonnant". Trecho retirado de um editorial do Le Devoir no qual se coloca que a gestão do serviço público obedece a imperativos políticos, em lugar de observar a qualidade dos serviços à população. Na época da publicação, quando ocorreu a indicação de um novo gestor regional para a RSSSQ, o jornal defendeu a idéia de que o eleito enfrentaria muitos conflitos, preconceitos e problemas com a baixa motivação dos executivos para o trabalho. 